\title{
Suscetibilidade à azitromicina de agentes bacterianos isolados de processos infecciosos em diferentes sítios de animais de companhia
}

\author{
[Azithromycin susceptibility pattern of bacterial isolated from different sites of infections in pet animals] \\ I.A. Pereira ${ }^{1}$, L.C. Soares ${ }^{1}$, S.M.O. Coelho ${ }^{1}$, F.A. Balbino ${ }^{2}$, B.R. Pribul ${ }^{2}$, M.M.S. Souza ${ }^{3 *}$ \\ ${ }^{1}$ Aluno de pós-graduação - UFRRJ - Seropédica, RJ \\ ${ }^{2}$ Aluno de graduação - UFRRJ - Seropédica, RJ \\ ${ }^{3}$ Departamento de Microbiologia e Imunologia Veterinária - UFRRJ \\ 23890-000 - Seropédica, RJ
}

\begin{abstract}
RESUMO
Avaliou-se o perfil de suscetibilidade bacteriana de diferentes sítios infecciosos frente aos antimicrobianos de eleição e determinaram-se o perfil de atividade in vitro e a concentração inibitória mínima (CIM) da azitromicina. Diferentes testes fenotípicos detectaram resistência à azitromicina em $45 \%$ de Staphylococcus spp. e $65 \%$ dos bastonetes Gram-negativo. A CIM $_{50}$ para $S$. aureus foi $4,0 \mu \mathrm{g} / \mathrm{mL}$ para $S$. intermedius $1,0 \mu \mathrm{g} / \mathrm{mL}$, Staphylococcus spp. coagulase-negativo $\geq 512 \mu \mathrm{g} / \mathrm{mL}$ e bastonetes Gram-negativo $256 \mu \mathrm{g} / \mathrm{mL}$. Investigou-se, também, uma possível resistência cruzada entre oxacilina e azitromicina por meio da detecção do gene mec $A$ em Staphylococcus spp. Foi possível detectar resistência à azitromicina em nove (15\%) isolados de Staphylococcus spp. mecA positivo.
\end{abstract}

Palavras-chave: cão, gato, resistência bacteriana, azitromicina

\begin{abstract}
Antimicrobials susceptibility pattern of bacterial isolated from different sites of infection, in vitro azithromycin activity pattern, and its minimum inhibitory concentration (MIC) values were evaluated. Different phenotypic tests detected azithromycin resistance in $45 \%$ of Staphylococcus spp. and $65 \%$ of resistant Gram-negative rods. $M I C_{50}$ was $4.0 \mu \mathrm{g} / \mathrm{mL}$ for Staphylococcus aureus, $1.0 \mu \mathrm{g} / \mathrm{mL}$ for S. intermedius, $\geq 512.0 \mu \mathrm{g} / \mathrm{mL}$ for coagulase negative Staphylococcus, and $256.0 \mu \mathrm{g} / \mathrm{mL}$ for Gram-negative rods. In addition, it was investigated the possible cross-resistance between oxacillin and azithromycin, by detection of mecA gen in Staphylococcus spp. Nine (15\%) mecA-positive Staphylococcus spp. were also phenotypically resistant to azithromycin.
\end{abstract}

Keywords: dog, cat, antimicrobial resistance, azithromycin

\section{INTRODUÇÃO}

A azitromicina é amplamente utilizada no tratamento de infecções em humanos e está disponível, atualmente, no mercado veterinário, como alternativa de tratamento em processos infecciosos dos sistemas genito-urinário, respiratório, oral e pele (Retsema, 1999). Seu mecanismo de ação é bacteriostático e consiste na ligação à subunidade $50 \mathrm{~S}$ do ribossomo, inibindo, assim, a síntese proteica. Apresenta atividade contra bactérias aeróbias e anaeróbias Grampositivo, com exceção de enterococos, e contra

Recebido em 2 de julho de 2008

Aceito em 8 de abril de 2009

*Autor para correspondência (corresponding author)

E-mail: miliane@ufrrj.br
Gram-negativo (Girard et al., 1990; Neu, 1991). A reorganização estrutural deste fármaco confere características farmacocinéticas e microbiológicas diferenciais, podendo ser absorvida por via oral e parenteral em dose única diária e em ciclos de tratamento curtos, fato este que favorece seu amplo uso na terapêutica veterinária.

O uso indiscriminado de antibióticos na clínica veterinária, sem execução de testes de sensibilidade que possibilitem a utilização do fármaco ideal, contribui para o aumento do espectro de microrganismos com habilidade de suplantar os mecanismos de ação desses fármacos. 
A conduta clínica veterinária colabora com o aumento do uso de antimicrobianos de amplo espectro, favorecendo casos de resistência (Prescott et al., 2002). Nesse contexto, a azitromicina tem sido amplamente utilizada, porém a maioria dos estudos que avaliaram o desenvolvimento de sua resistência foi realizada a partir de isolados bacterianos de origem humana. Assim, são necessários estudos que avaliem o espectro de atividade da azitromicina frente a bactérias provenientes de infecções animais.

O aumento da pressão seletiva na população bacteriana também induz alguns mecanismos de resistência cruzada como os observados em $S$. aureus e Staphylococcus spp. coagulase-negativos eritromicina e oxacilina-resistentes (Neu, 1991). O mecanismo envolvido na resistência à oxacilina pode ser definido pela expressão do gene mecA que codifica uma nova proteína-alvo para a penicilina a qual foi denominada PBP2a ou PBP2'. A transferência horizontal do gene mecA em Staphylococcus spp. resultou na disseminação mundial de clones oxacilina e multidrogaresistentes. A literatura aponta a presença deste gene como um possível mecanismo comum de resistência à oxacilina e à azitromicina.

O presente estudo teve como objetivos avaliar o espectro de atividade da azitromicina frente a diversos processos infecciosos bacterianos de animais de companhia, e avaliar a concentração inibitória mínima (CIM) e a possível resistência cruzada entre oxacilina e azitromicina em isolados de Staphylococcus spp.

\section{MATERIAL E MÉTODOS}

Foram obtidas 151 amostras de diferentes processos infecciosos, 128 de cães e 23 de gatos, por meio do acompanhamento da rotina de atendimento clínico do Departamento de Clínica Médica de Pequenos Animais da Universidade Estácio de Sá e de visitas periódicas ao Instituto Veterinário Municipal Jorge Waitsman, no período de outubro de 2005 a março de 2006. Dentre os processos infecciosos avaliados, foram coletadas amostras em: 33 cães com otite externa; 25 cães e oito gatos com lesões e secreções da pele; 34 cães e 15 gatos clinicamente suspeitos de infecção urinária; seis cadelas com piometra; cinco cães que apresentavam quadros de infecção do trato respiratório; 12 cães com periodontites, lesões pustulares e fistulares provocadas por infecção dos dentes pré-molares e molares superiores e em 13 cães com alterações patológicas da mucosa conjuntival, tais como: secreções purulentas e úlceras de córnea.

As amostras foram enviadas, sob refrigeração, para o laboratório, para análises microbiológicas. As amostras clínicas foram inoculadas em ágar sangue ( $5 \%$ de sangue de carneiro) e em meios seletivos e diferenciais. As colônias isoladas foram submetidas ao método de Gram, teste da catalase e hidróxido de potássio a $3 \%$ e processadas de acordo com os testes de identificação específicos para cada grupo bacteriano (Koneman et al., 2001). Posteriormente, foram realizados os testes de suscetibilidade aos fármacos pela técnica de difusão em disco ${ }^{1}$ (Methods..., 2005) tendo sido a escolha dos antimicrobianos $^{1}$ realizada segundo indicações terapêuticas para cada um dos sítios de infecção.

Para a realização dos ensaios de suscetibilidade à azitromicina, empregou-se, primeiro, o teste de difusão em disco, sendo utilizados discos de azitromicina de $15 \mu \mathrm{g}^{1}$. De acordo com o padrão estabelecido pelo CLSI (Methods..., 2005), os halos de inibição correspondem a diâmetros $\leq 13 \mathrm{~mm}$ para isolados resistentes, $\geq 18 \mathrm{~mm}$ para sensíveis e o intervalo de $14-17 \mathrm{~mm}$ para isolados com grau de inibição intermediário. Os testes de microdiluição em caldo e em ágar também foram aplicados para a avaliação da atividade inibitória e para a determinação da CIM da azitromicina. Dessa maneira, foram estabelecidas as seguintes concentrações de azitromicina: $1.0 \mu \mathrm{L} / \mathrm{mL}$; $2,0 \mu \mathrm{L} / \mathrm{mL} ; \quad 4,0 \mu \mathrm{L} / \mathrm{mL} ; \quad 8,0 \mu \mathrm{L} / \mathrm{mL} ; \quad 16,0 \mu \mathrm{L} / \mathrm{mL} ;$ $32,0 \mu \mathrm{L} / \mathrm{mL} ; 64,0 \mu \mathrm{L} / \mathrm{mL} ; 128,0 \mu \mathrm{L} / \mathrm{mL} ; 256,0 \mu \mathrm{L} / \mathrm{mL}$ e $512,0 \mu \mathrm{L} / \mathrm{mL}$, Os isolados que apresentaram CIM maior ou igual a $8,0 \mu \mathrm{g} / \mathrm{mL}$ foram considerados resistentes (Methods..., 2005). As amostras padrão de $S$. aureus sensível (ATCC 25923) e resistente à oxacilina (ATCC 29213) foram utilizadas como controle dos testes.

Para avaliar a possível resistência cruzada entre oxacilina e azitromicina em isolados de Staphylococcus spp., foi realizada a detecção do gene $m e c A$, frequentemente associado à resistência à oxacilina em Staphylococcus spp., utilizando-se a técnica de reação em cadeia de polimerase (PCR) descrita por Coelho et al. (2007).

Análises estatísticas foram aplicadas para a determinação da concentração inibitória mínima (CIM) da azitromicina. Aplicou-se a regressão logística, conforme Ritz e Streibig (2005),

\footnotetext{
${ }^{1}$ Sensifar-Cefar, Brasil.
} 
utilizando o software R2.4.1/2006 e análise estatística multivariada (correlação canônica), para estabelecer a correspondência entre os resultados dos testes fenotípicos e determinar quais isolados realmente foram resistentes (Hair et al., 2005).

\section{RESULTADOS E DISCUSSÃO}

Observou-se prevalência de $36,8 \%$ de Staphylococcus spp. coagulase-positivo (ECP), seguidos pelas enterobactérias, 30,5\%, Staphylococcus spp. coagulase-negativo, 8,3\%, e Pseudomonas spp., 6,9\% (Tab. 1). Staphylococcus intermedius foi prevalente em casos de otite externa e pioderma canino, seguidos por $S$. aureus e $S$. schleiferi, sendo essas as espécies frequentemente apontadas na etiologia desses processos infecciosos (Pelerim et al., 1998; Hariharan et al., 2006). Dentre as enterobactérias, Escherichia coli foi prevalente nas infecções urinárias e apresentou percentuais de isolamento significativos nas infecções da pele e do conduto auditivo. Outras espécies isoladas foram: Proteus spp., Serratia spp., Citrobacter freundii, Yersinia spp., Enterobacter spp. e Salmonella spp. Estudos anteriores também relataram o isolamento de ampla diversidade de espécies bacterianas em processos infecciosos de cães (Kogika et al., 1995; Çetin et al., 2003; Coggan et al., 2004). Listeria spp. foi isolada em amostras de dois cães que, após envolvimento em uma briga, desenvolveram processos infecciosos como uveíte traumática, secreção nasal mucopurulenta e lesões fistulares. O isolamento de Listeria spp., em todos os sítios avaliados, permite estabelecer o envolvimento e a via de contaminação. A condição higiênico-sanitária do local de alojamento desses cães deve ter associação direta com a presença desse agente, uma vez que Listeria spp. pode ser isolada a partir de solos, silagem, esgoto, água corrente e fezes (Hirsh e Zee, 2003). A diversidade de espécies bacterianas isoladas aponta para a importância do diagnóstico microbiológico como fator limitante das falhas de conduta terapêutica.

Tabela 1. Percentual de microrganismos isolados a partir dos processos infecciosos de animais de companhia

\begin{tabular}{|c|c|c|c|c|c|c|c|}
\hline \multirow{2}{*}{$\begin{array}{l}\text { Número de isolados/ } \\
\text { sítio infeccioso avaliado }\end{array}$} & Otite & Pele & $\begin{array}{c}\text { Trato } \\
\text { urinário }\end{array}$ & $\begin{array}{c}\text { Trato } \\
\text { respiratório }\end{array}$ & $\begin{array}{c}\text { Trato } \\
\text { reprodutivo }\end{array}$ & $\begin{array}{c}\text { Mucosa } \\
\text { oral }\end{array}$ & $\begin{array}{c}\text { Mucosa } \\
\text { ocular }\end{array}$ \\
\hline & $\mathrm{n}=49$ & $\mathrm{n}=40$ & $\mathrm{n}=29$ & $\mathrm{n}=5$ & $\mathrm{n}=10$ & $\mathrm{n}=6$ & $\mathrm{n}=8$ \\
\hline \multicolumn{8}{|l|}{$\begin{array}{l}\text { Staphylococcus spp. } \\
\text { coagulase-positivo }\end{array}$} \\
\hline S. intermedius & 26,5 & 27,5 & 17,2 & - & 10 & 16,7 & 25 \\
\hline S. aureus subsp. aureus & 8,2 & 15 & - & - & 10 & - & 25 \\
\hline S. aureus subsp. anaerobius & - & - & - & - & 10 & - & - \\
\hline S. schleiferi subsp. coagulans & 4,1 & 10 & - & - & - & - & - \\
\hline \multicolumn{8}{|l|}{$\begin{array}{l}\text { Staphylococcus spp. } \\
\text { coagulase-negativo }\end{array}$} \\
\hline S. xylosus & 8,2 & 5 & - & - & & 16,7 & - \\
\hline S. hominis & - & 5 & - & - & 10 & - & - \\
\hline S. epidermidis & - & - & - & 40 & - & - & - \\
\hline Micrococcus spp. & 14,3 & 7,5 & - & - & - & - & - \\
\hline Streptococcus spp. & - & - & - & - & - & 16,7 & - \\
\hline \multicolumn{8}{|l|}{ Bastonetes Gram-positivo } \\
\hline Corynebacterium spp. & 2,1 & 2,5 & 3,4 & 20 & 20 & 16,7 & - \\
\hline Listeria spp. & - & - & 3,4 & 40 & - & 16,7 & 25 \\
\hline Bacillus spp. & - & - & 10,3 & - & - & - & - \\
\hline \multicolumn{8}{|l|}{ Bastonetes Gram-negativo } \\
\hline Pseudomonas aeruginosa & 14,3 & 2,5 & - & - & 10 & - & 12,5 \\
\hline E. coli & 6,1 & 5 & 24,1 & - & - & - & - \\
\hline P. mirabilis & 6,1 & 5 & 13,8 & - & - & 16,7 & - \\
\hline P. vulgaris & - & 2,5 & - & - & - & - & \\
\hline S. marcescens & 6,1 & 7,5 & 3,4 & - & 10 & - & - \\
\hline S. liquefaciens & - & - & - & - & - & - & 12,5 \\
\hline C. freundii & - & 2,5 & 10,3 & - & 10 & - & - \\
\hline Y. enterocolitica & - & 2,5 & 6,9 & - & - & - & - \\
\hline Salmonella spp. & - & - & 3,4 & - & - & - & - \\
\hline Enterobacter spp. & - & - & - & - & 10 & - & - \\
\hline Levedura & 4,1 & - & 3,4 & - & - & - & - \\
\hline
\end{tabular}


O perfil de suscetibilidade antimicrobiana observado variou em relação aos sítios de infecção investigados. No caso dos isolados provenientes de otite externa canina, os antibióticos mais eficientes foram a associação de ampicilina+sulbactam, cefalotina e gentamicina (Tab. 2). Nas infecções do trato urinário, os melhores resultados obtidos foram para ampicilina+sulbactam, gentamicina e fluoroquinolonas, como norfloxacina e ciprofloxacina. Nas infecções da pele, ampicilina+sulbactam, ciprofloxacina, cefotaxima e cefalexina apresentaram menores percentuais de resistência. Foram detectados altos percentuais de resistência em relação à penicilina e à oxacilina em todos os isolados.

Tabela 2. Percentual de suscetibilidade de antimicrobianos dos principais grupos bacterianos isolados de infecções de animais de companhia

\begin{tabular}{|c|c|c|c|c|c|c|c|c|c|c|}
\hline \multirow{2}{*}{ Antimicrobiano } & \multicolumn{5}{|c|}{ Otite externa canina } & \multicolumn{3}{|c|}{ Infecções de pele } & \multicolumn{2}{|c|}{ UTI } \\
\hline & ECP & $\mathrm{ECN}$ & MIC & PSD & ENT & ECP & $\mathrm{ECN}$ & ENT & ECP & ENT \\
\hline \multicolumn{11}{|l|}{ Beta-lactâmicos } \\
\hline Cefoxitina & 5,3 & 25 & 0 & 42,8 & 0 & 5,8 & 0 & 54,5 & - & - \\
\hline Cefalotina & 5,3 & 25 & 0 & 57,1 & 11,1 & - & - & - & - & - \\
\hline Ceftriaxona & - & - & - & - & - & 0 & 0 & 54,5 & 0 & 41,2 \\
\hline Oxacilina & 36,8 & 100 & 14,3 & 100 & 100 & 17,6 & 25 & 90,9 & 100 & 100 \\
\hline Ampicilina & 78,4 & 75 & 14,3 & 100 & 88,9 & 76,5 & 100 & 72,7 & 100 & 100 \\
\hline Amp+sulbactam & 0 & 25 & 0 & 14,3 & 0 & 0 & 0 & 0 & 0 & 4 \\
\hline Penicilina G & 78,4 & 75 & 42,8 & 100 & 88,9 & 82,5 & 100 & 90,9 & 100 & 100 \\
\hline Vancomicina & 26,3 & 50 & 0 & 57,1 & 88,9 & 11,8 & 0 & 90,9 & 33,3 & 100 \\
\hline Amoxicilina & 47,4 & 50 & 28,5 & 57,1 & 66,7 & - & - & - & 66,7 & 15 \\
\hline \multicolumn{11}{|l|}{ Aminoglicosídeos } \\
\hline Gentamicina & 0 & 25 & 0 & 0 & 0 & - & - & - & 0 & 0 \\
\hline Neomicina & 42,1 & 25 & 14,3 & 42,8 & 55,5 & - & - & - & - & - \\
\hline \multicolumn{11}{|l|}{ Macrolídeos } \\
\hline Azitromicina & 42,1 & 50 & 28,5 & 42,8 & 44,4 & 52,9 & 50 & 100 & - & - \\
\hline Eritromicina & - & - & - & - & - & 88,2 & 100 & 100 & - & - \\
\hline \multicolumn{11}{|l|}{ Quinolonas } \\
\hline Enrofloxacina & 26,3 & 25 & 28,5 & 14,3 & 44,4 & 17,6 & 0 & 27,3 & 100 & 35,3 \\
\hline Norfloxacina & - & - & - & - & - & - & - & - & 0 & 35,3 \\
\hline Ciprofloxacina & - & - & - & - & - & 17,6 & 0 & 18,2 & 0 & 29,4 \\
\hline \multicolumn{11}{|l|}{ Outros } \\
\hline Cloranfenicol & 5,3 & 0 & 0 & 42,8 & 22,2 & 0 & 50 & 36,4 & - & - \\
\hline Clindamicina & - & - & - & - & - & 23,5 & 25 & 100 & - & - \\
\hline Nitrofurantoína & - & - & - & - & - & - & - & - & 0 & 0 \\
\hline
\end{tabular}

ECP: Staphylococcus spp. coagulase-positivo; ECN: Staphylococcus spp. coagulase-negativo; MIC: Micrococcus spp.; PSD: Pseudomonas spp.; ENT; enterobactérias.

O perfil de atividade da azitromicina, segundo o teste de difusão em disco, detectou 48,6\% $(52 / 107)$ de isolados resistentes à azitromicina. $\mathrm{O}$ percentual de resistência em $S$. intermedius correspondeu a 40\% (12/30), em $S$. aureus foi de $55,6 \%(10 / 18)$, em ECN $50 \%(6 / 12)$ e para bastonetes Gram-negativo, 55,3\% (27/50). O teste de microdiluição em caldo detectou valores de CIM acima ou igual ao limite de resistência à azitromicina em 53,3\% (16/30) dos isolados de $S$. intermedius, em 50\% (9/18) de $S$. aureus, em
$66,7 \%(8 / 12)$ de ECN e em 90\% (45/50) dos bastonetes Gram-negativo. A técnica da diluição em ágar detectou 88,9\% (16/18) dos isolados de $S$. aureus resistentes à azitromicina e $83,3 \%$ $(25 / 30)$ e $75 \%(9 / 12)$ de $S$. intermedius e ECN, respectivamente. O percentual de resistência dos bastonetes Gram-negativo permaneceu inalterado em relação ao teste de microdiluição em caldo. Dados na literatura, a respeito do desenvolvimento de resistência à azitromicina, em clínica veterinária, são escassos até o 
momento. No entanto, alguns estudos em populações humanas mostraram que cepas de $S$. aureus apresentaram aumento da CIM de três diluições, após serem submetidas a nove exposições consecutivas de azitromicina (Retsema, 1999).

A determinação da $\mathrm{CIM}_{50}$, para a azitromicina obtida a partir da técnica de microdiluição em caldo para os isolados de $S$. aureus, apresentou valores de $4,0 \mu \mathrm{g} / \mathrm{mL}$, para $S$. intermedius foi de $1,0 \mu \mathrm{g} / \mathrm{mL}$ e para ECN valores acima de $512,0 \mu \mathrm{g} / \mathrm{mL}$. A $\mathrm{CIM}_{90}$ apresentou valores de $8,0 \mu \mathrm{g} / \mathrm{mL}$ para $S$. aureus e valores maiores que $512,0 \mu \mathrm{g} / \mathrm{mL}$ para $S$. intermedius e ECN, respectivamente (Fig. 1). Em relação aos bastonetes Gram-negativo, os resultados da
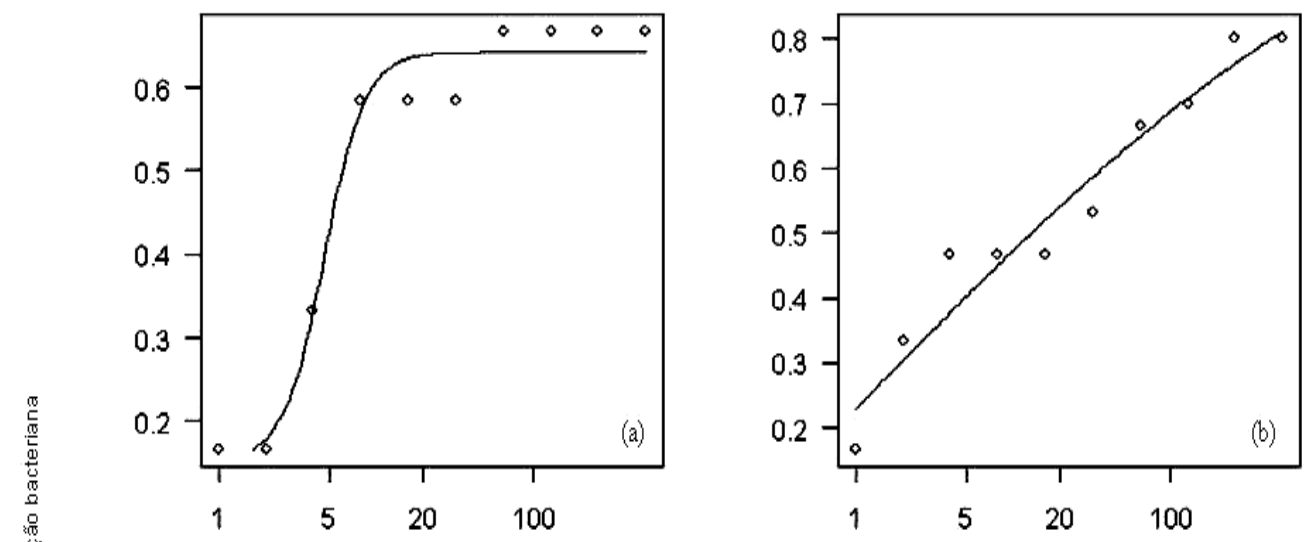

$\mathrm{CIM}_{50}{ }_{90}$, detectados pela técnica de microdiluição em caldo, foram de $256,0 \mu \mathrm{g} / \mathrm{mL}$ e $>512,0 \mu \mathrm{g} / \mathrm{mL}$ (Fig. 1). Entretanto, os altos valores observados podem estar associados à presença de enterobactérias e Pseudomonas spp. reconhecidamente resistentes à azitromicina. A $\mathrm{CIM}_{50} /_{90}$ também foi avaliada pela técnica de diluição em ágar, e os resultados obtidos foram: $16,0 \mu \mathrm{g} / \mathrm{mL}$ e $64,0 \mu \mathrm{g} / \mathrm{mL}$ para $S$. aureus, $16,0 \mu \mathrm{g} / \mathrm{mL}$ e $32,0 \mu \mathrm{g} / \mathrm{mL}$ para $S$. intermedius, $32,0 \mu \mathrm{g} / \mathrm{mL}$ e $128,0 \mu \mathrm{g} / \mathrm{mL}$ para ECN. Para os bastonetes Gram-negativo, a $\mathrm{CIM}_{50} / 90$ foi de $256,0 \mu \mathrm{g} / \mathrm{mL}$ e $>512,0 \mu \mathrm{g} / \mathrm{mL}$, e o perfil de inibição só atingiu níveis significativos em alta concentração de azitromicina.
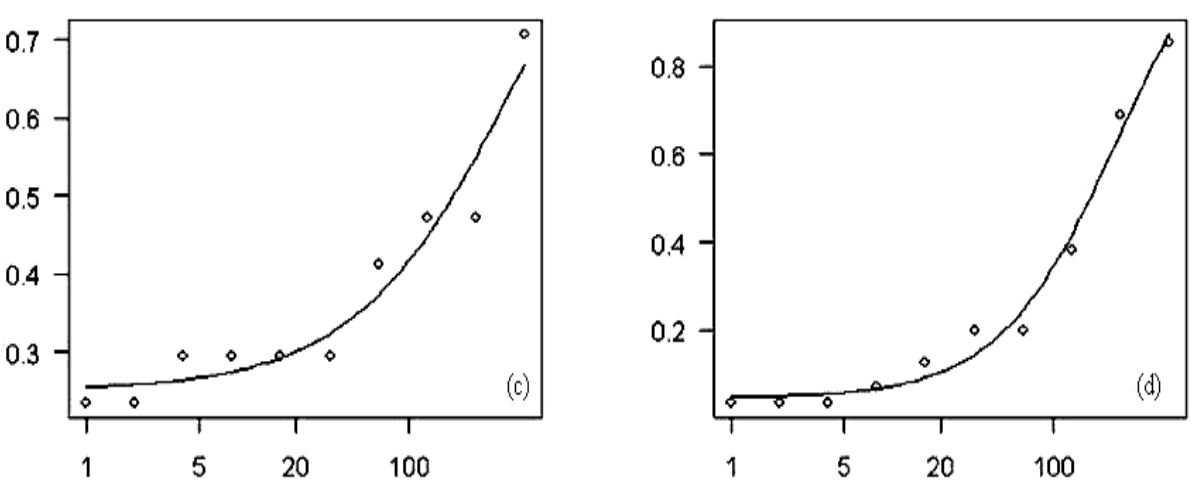

Concentração $\mu g / \mathrm{mL}$

Figura 1. Perfil de atividade da azitromicina, segundo resultados obtidos no teste de microdiluição em caldo obtido e amostras isoladas de infecções de animais de companhia. 


\section{Pereira et al.}

Modelo dose-resposta (concentração de azitromicina x inibição bacteriana) dos isolados, (a) S. aureus, (b) S. intermedius, (c) ECN, (d) bastonetes Gram-negativo avaliados pelo teste de microdiluição em caldo.

Os resultados de determinação da resistência à azitromicina, obtidos pelas três técnicas, foram submetidos à correlação canônica, para estabelecer a correspondência, de forma a determinar quais isolados foram realmente resistentes (Hair et al., 2005). Os isolados que apresentaram escores de correspondência acima de 0,5 são considerados potencialmente resistentes. Dessa maneira, $45 \%$ dos isolados de Staphylococcus spp. e $65,4 \%$ dos bastonetes Gram-negativo podem ser considerados verdadeiramente resistentes por apresentarem grau de correspondência de $86,6 \%$ e $91,3 \%$ respectivamente. Em relação aos bastonetes Gram-negativo, $\quad 65,4 \% \quad$ dos isolados apresentaram grau de correspondência de 91,3\%. Os testes fenotípicos detectaram que $35 \%$ $(21 / 60)$ dos isolados foram sensíveis e $5 \%(3 / 60)$ resistentes, em todos os testes fenotípicos.

Após análise fenotípica da resistência à oxacilina e azitromicina, as cepas foram avaliadas quanto à presença do gene $m e c A$, pela técnica de PCR (Fig. 2). Do total de 60 isolados de Staphylococcus spp. avaliados, nove (15\%) foram positivos para a presença do gene $m e c A$, tendo estes apresentado variados perfis de suscetibilidade à oxacilina e à azitromicina nesses isolados (Tab. 3).

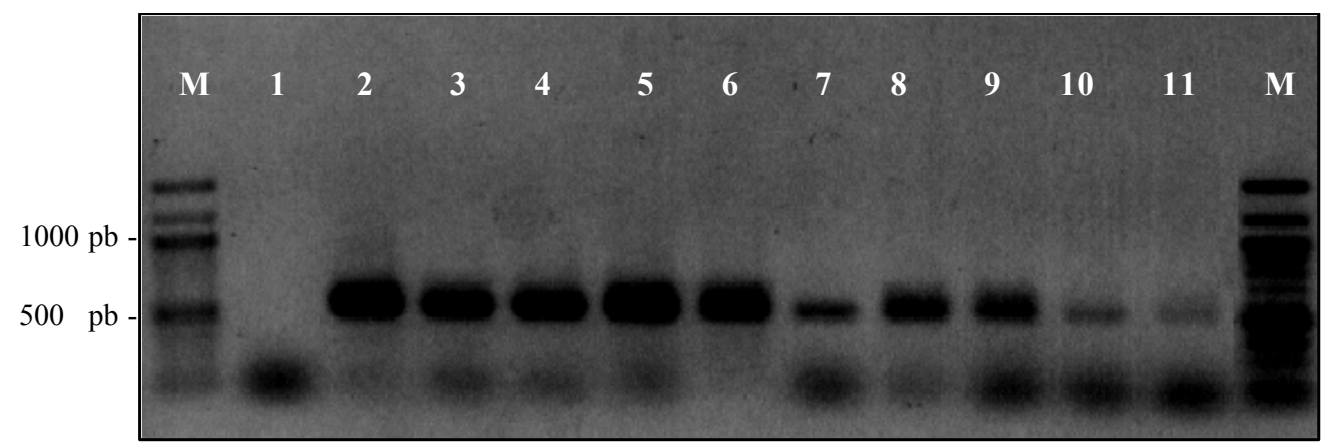

Figura 2. Eletroforese do fragmento do gene mecA (513pb) de amostras de Staphylococcus spp. isoladas de processos infecciosos de animais de companhia, em gel de agarose a 1,5\%. (M) marcador de peso molecular (100pb), (1) controle negativo, (2) controle positivo, (3) até (11) Staphylococcus spp. mecA positivo.

Tabela 3. Perfil de suscetibilidade à azitromicina e à oxacilina dos Staphylococcus spp. mecA positivos obtido de amostras de infecções de animais de companhia

\begin{tabular}{cccccccccc}
\hline & \multicolumn{4}{c}{ Oxacilina } & \multicolumn{4}{c}{ Azitromicina } \\
\hline Staphylococcus spp. mecA positivo & DD & DDM & AS & MC & DA & DD & MC & DA \\
\hline 1 & S & S & S & S & S & R & R & R \\
2 & $\mathrm{R}$ & R & R & R & S & R & S & S \\
3 & $\mathrm{~S}$ & S & S & S & R & R & R & R \\
4 & $\mathrm{~S}$ & S & S & S & S & R & S & R \\
5 & $\mathrm{R}$ & $\mathrm{R}$ & $\mathrm{R}$ & $\mathrm{S}$ & $\mathrm{S}$ & $\mathrm{S}$ & $\mathrm{S}$ & $\mathrm{R}$ \\
6 & $\mathrm{~S}$ & $\mathrm{R}$ & $\mathrm{R}$ & $\mathrm{R}$ & $\mathrm{R}$ & $\mathrm{S}$ & $\mathrm{R}$ & $\mathrm{R}$ \\
7 & $\mathrm{~S}$ & $\mathrm{~S}$ & $\mathrm{~S}$ & $\mathrm{~S}$ & $\mathrm{~S}$ & $\mathrm{R}$ & $\mathrm{R}$ & $\mathrm{R}$ \\
8 & $\mathrm{R}$ & $\mathrm{R}$ & $\mathrm{S}$ & $\mathrm{S}$ & $\mathrm{R}$ & $\mathrm{S}$ & $\mathrm{S}$ & $\mathrm{R}$ \\
9 & $\mathrm{R}$ & $\mathrm{R}$ & $\mathrm{S}$ & $\mathrm{S}$ & $\mathrm{R}$ & $\mathrm{S}$ & $\mathrm{R}$ & $\mathrm{S}$ \\
\hline
\end{tabular}

DD: difusão em disco, DDM: difusão em disco modificada, AS: ágar screen, MC: microdiluição em caldo, DA: diluição em ágar. 
O perfil heterogêneo de resistência à oxacilina, observado nos isolados mecA positivo, é suportado pelas diferenças de características de crescimento em que, possivelmente, numa população heterorresistente, existem tanto organismos suscetíveis que exibem crescimento atípico de estafilococos não-heterorresistentes, quanto organismos resistentes (Aarestrup et al., 2001). Estudos relatam que espécies estafilocócicas mecA positivo apresentam instabilidade genética e podem perder o gene, resultando em subpopulações sensíveis. Logo, a diferença dos resultados de avaliação fenotípica da resistência à oxacilina deve ser utilizada como alerta para a comunidade científica, uma vez que inúmeros fatores de instabilidade das espécies devem ser levados em consideração antes de classificá-las como sensíveis ou resistentes ao antibiótico (Sakoulas et al., 2001). Além da presença do gene $m e c A$, a expressão fenotípica heterogênea da resistência à oxacilina pode ser explicada pela hiperprodução de beta-lactamase ou pela modificação de afinidade a outras "PBPs", principalmente a PBP3 (Brown et al., 2001; Petinaki et al., 2001). Recentemente, a literatura aponta também para a detecção do gene femA que codifica um fator essencial para a resistência à meticilina, universalmente presente em S. aureus (Mehrotra et al., 2001). No entanto, foi possível observar que todos os nove isolados mecA positivo avaliados apresentaram, pelo menos em um dos testes fenotípicos realizados, resistência à azitromicina. Tais resultados corroboram com a ideia de uma possível resistência cruzada entre oxacilina e azitromicina em isolados de Staphylococcus spp., reduzindo, assim, a eficiência da azitromicina quando estes agentes estão envolvidos na etiologia de processos infecciosos de animais de companhia.

\section{CONCLUSÕES}

O perfil de suscetibilidade à azitromicina, que variou de $48,6 \%$ e $55 \%$ em relação aos sítios de infecção investigados, justifica a adoção de protocolos de identificação e antibiogramas, antes da eleição desse fármaco na terapêutica clínico-veterinária. Nove $(15 \%)$ isolados de Staphylococcus spp. positivos para a presença do gene $m e c A$, considerado padrão-ouro da resistência à oxacilina, foram resistentes à azitromicina nos testes fenotípicos avaliados; assim, é possível haver um mecanismo de resistência cruzada.

\section{REFERÊNCIA BIBLIOGRÁFICA}

AARESTRUP, F.M.; SEYFARTH, A.M.; EMBORG, $H$. et al. Effect of abolishment of the use of antimicrobial agents for growth promotion on occurrence of antimicrobial resistance in fecal enterococci from food animals in denmark. Antimicrob. Agents Chemother., v.45. p.20542059, 2001.

BROWN, D.F.J.; EDWARDS, D.I.; HAWKEY, P.M. et al. On behalf of the joint working party of the britis, guidelines for the laboratory diagnosis and susceptibility testing of methicillin-resistant Staphylococcus aureus (MRSA). J. Antimicrob. Chemother., v.56, p.1000-1018, 2001.

ÇETIN, C.; SENTÜRK, S.; KACABIYIK, A.L. et al. Bacteriological examition of urines samples from dogs with symptoms of urinary tract infection. Turk. J. Vet. Anim. Sci., v.23, p.12251229, 2003.

COELHO, S.M.O.; MENEZES, R.A.; SOARES, L.C. et al. Mapeamento do perfil de resistência e detecção do gene mecA em Staphylococcus aureus e $S$. intermedius oxacilina-resistentes isolados de humanos e animais. Cienc. Rural, v.37, p.195-200, 2007.

COGGAN, J.A.; OLIVEIRA, C.M.; FAUSTINO, M. et al. Estudo microbiológico de conteúdo intrauterino de cadelas com piometra e pesquisa de fatores de virulência em cepas de Escherichia coli. Arq. Inst. Biol., v.71, supl., p.1749, 2004.

GIRARD, A.E.; GIRARD, D.; RETSEMA, J.A. Correlation of the extravascular pharmacokinetics of Azithromycin with in vivo efficacy in models of localized infection. $J$. Antimicrob. Chemother., v.25, suppl.A, p.61-71, 1990.

HAIR, J.F.; ANDERSON, R.E.; TATHAM, R.L. et al. Análise multivariada de dados, 5.ed. Porto Alegre: Bookman, 2005.

HARIHARAN, H.; COLES, M.; POOLE, D. et al. Update on microbial susceptibilities of bacterial isolates from canine and feline otitis externa. Can. Vet. J., v.47, p.253-257, 2006.

HIRST, D.C.; ZEE, Y.C. Microbiologia veterinária. Rio de Janeiro. Guanabara Koogan, 2003. p.212-215. 
KONEMAN, E.W.; ALLEN, S.D.; JANDA, W.M. et al. Diagnóstico microbiológico. 5.ed. Rio de Janeiro: MEDSI. p.1465, 2001.

KOGIKA, M.M.; FORTUNATO, V.A.B.; MAMIZUKA, E.M. et al. Etiologic study of urinary tract infection in dogs. Braz. J. Vet. Res. Anim. Sci., v.32, p.31-36, 1995.

MEHROTRA, M.; WANG., G.; JOHNSON, W.M. Multiplex PCR for detection of genes for Staphylococcus aureus enterotoxins, exfoliative toxins, toxic shock syndrome toxin 1, and methicillin resistance, J. Clin. Microbiol., v.38, p.1032-1035, 2001.

METHODS for dilution antimicrobial susceptibility tests for bacteria that grow aerobically. Approved standards. Wayne, PA: CLSI, 2005. (Document M45-P).

NEU, H.C. Clinical microbiology of azithromycin. Am. J. Med., v.91, suppl.3A, p.3A12S, 1991.

PELLERIN, J.L.; BOURDEAU, P.; SEBBAG, $\mathrm{H}$. et al. Epidemiosurveillance of antimicrobial compound resistance of Staphylococcus intermedius clinical isolates from canine pyoderma. Comp. Immunol. Microbiol. Infect. Dis., v.21, p.115-133, 1998.

PETINAKI， E.; DIMITRACOPOULOS， G.; SPILIOPOULOU, I. Decreased affinity of PBP3 to methicillin in a clinical isolate of Staphylococcus epidermidis with borderline resistance to methicillin and free of the mecA gene. Microb. Drug Resist., v.7, p.297-300, 2001.

PRESCOTT, J.F.; HANNA, W.J.B.; REIDSMITH, R. Antimicrobial drug use and resistance in dogs. Can. Vet. J., v.43, p.107-116, 2002.

RETSEMA, J.A. Susceptibility and resistance emergence studies with Macrolides. Int. J. Antimicrob. Agents, v.11, suppl.1, p.S15-S21, 1999.

RITZ, C.; STREIBIG, J.C. Bioassay analysis using R. J. Stat. Softw., v.12, p.1-22, 2005.

SAKOULAS, G.; GOLD H.S.; VENKATARAMAN, L. et al. MethicillinResistant Staphylococcus aureus: Comparison of Susceptibility Testing Methods and Analysis of mecA-Positive Susceptible Strains. J. Clin. Microbiol., v.39, p.3946-3951, 2001. 